\title{
PENGEMBANGAN SELF ACCESS CENTER (SAC) UNTUK MEMFASILITASI ANAK PUTUS SEKOLAH PADA USIA PENDIDIKAN DASAR DI KECAMATAN CIPATUJAH KABUPATEN TASIKMALAYA
}

\author{
Sylvia Rabbani \\ IKIP Siliwangi \\ sylviarabbani@gmail.com
}

\begin{abstract}
ABSTRAK
Secara umum, tujuan jangka panjang program pengabdian ini adalah mengembangkan Self Access Center(SAC) untuk menfasilitasi anak putus sekolah usia pendidikan dasar di Kecamatan Cipatujah Kabupaten Tasikmalaya. Secara khusus, target khusus yang ingin dicapaisebagai berikut: (1). Memfasilitasi anakanak putus sekolah yang berada pada usia pendidikan dasar agar tetap dapat belajar secara aman dan nyaman; (2). Memberikan layanan-layanan pendidikan yang dibutuhkan oleh anak-anak putus sekolah pada jenjang pendidikan dasar; (3) Membangun sinergi baik dengan orangtua dan sekolah agar anak-anak putus sekolah tersebut bisa kembali ke bangku sekolah. Metode yang akan dipakai dalam pencapaian tujuan tersebut sebagai berikut: (a). Mengumpulkan anakanak putus sekolah usia pendidikan dasar se-Kecamatan Cipatujah; (b). Memberikan gambaran umum mengenai kegiatan pengabdian yang akan dilakukan; (c). Melakukan refleksi dan diskusi mengenai berbagai kegiatan yang akan dilakukan di Self Access Center; (d). Melakukan kolaborasi dengan masyarakat sekitar dalam penentuan lokasiSelf Access Center; (e). Pelaksanaan kegiatan pembelajaran Self Access Center; (f). Evaluasi kegiatan Self Access Center.
\end{abstract}

Kata Kunci: Self Access Center, Anak Putus Sekolah, Pendidikan Dasar.

\begin{abstract}
In general, the long-term goal of this devotion program is to develop a Self Access Center (SAC) to facilitate primary school drop-outs in Cipatujah Subdistrict, Tasikmalaya District. Specifically, the specific targets to be pursued are as follows: (1). Facilitate dropout children who are at the age of primary education in order to keep learning safe and comfortable; (2). Providing educational services needed by drop-out children at elementary level; (3) Developing good synergy with parents and school so that the children drop out of school can go back to school. The methods to be used in achieving these objectives are as follows: (a). Collecting dropout children at elementary school age in Cipatujah sub-district; (b). Provides an overview of the activities of dedication to be performed; (c). Conduct reflection and discussion on various activities to be conducted in Self Access Center; (d). Collaborate with surrounding communities in determining the location of Self Access Center; (e). Implementation of Self Access Center learning activities; (f). Evaluation of Self Access Center activities.

Keywords: Self Access Center, Children Drop Out, Primary Education.
\end{abstract}




\section{A. PENDAHULUAN}

Gambaran umum Kecamatan Cipatujah Kabupaten Tasikmalaya berdasarkan data sosial dan budaya dapat digambarkan sebagai berikut: Data sosial dan budaya yang dimaksud adalah data fasilitas pendidikan (SD, SMP, SMA dan yang setara), jumlah keluarga miskin, dan jumlah rumah yang ada di Kabupaten Tasikmalaya.

Penduduk Kabupaten Tasikmalaya menurut Kepala Keluarga adalah sebanyak 423.094 KK. Dari jumlah tersebut 43.845 KK termasuk penduduk miskin, atau sekitar 10\% persen dari total penduduk di Kabupaten Tasikmalaya

Tersedianya Sumber Daya Manusia (SDM) yang berkualitas merupakan salah satu faktor utama keberhasilan pembangunan di suatu daerah. Peningkatan SDM lebih difokuskan pada pemberian kesempatan seluas-luasnya kepada penduduk untuk mengecap pendidikan. Oleh sebab itu, pemerintah Kabupaten Tasikmalaya berusaha secara konsisten berupaya meningkatkan SDM penduduk melalui jalur pendidikan. Upaya pemenuhan terhadap peningkatan tingkat pendidikan masyarakat di Kabupaten Tasikmalaya, salah satunya dengan cara penyediaan fasilitas pendidikan yang tersebar di beberapa kecamatan, khususnya Kecamatan Cipatujah.

Kasus yang terjadi di Kecamatan Cipatujah ini berdasarkan data secara umum yang telah diungkapkan sebelumnya dan pengamatan lapangan secara umum adalah banyaknya anak putus sekolah pada usia pendidikan dasar. Putus sekolah bukan merupakan salah satu permasalahan pendidikan yang tak pernah berakhir. Masalah ini telah berakar dan sulit untuk dipecahkan penyebabnya, tidak hanya karena kondisi ekonomi, tetapi ada juga yang disebabkan oleh kekacauan dalam keluarga, dan lain-lain. Hal ini juga dialami oleh beberapa anak di Kecamatan Cipatujah Kabupaten Tasikmalaya. Oleh karena itu, tim pengabdian PGSD STKIP Siliwangi ingin mengembangkan Self Access Center (SAC) untuk memfasilitasi anak putus sekolah usia pendidikan dasar.

Secara umum, masalah utamanya adalah kondisi ekonomi keluarga yang kurang mendukung. Sebagian lagi adalah faktor keluarga yang menyebabkan anak-anak putus sekolah. Adapun orang tua dan masyarakat dalam menghadapi anak putus sekolah ada dua yaitu upaya pencegahan dan upaya pembinaan. 


\section{B. LANDASAN TEORI}

Self Access Center (SAC) secara umum adalah pusat untuk mengakses berbagai pengetahuan secara mandiri tanpa bimbingan guru. Dengan SAC diharapkan murid, mahasiswa serta masyarakat umum dapat memperoleh materi dari berbagai ilmu dan dapat melatih diri untuk mengembangkan keterampilan berbahasa seluas-luasnya tanpa mengganggu dan diganggu oleh orang lain. Mereka juga bisa berlatih, menguji, dan mengoreksi diri sendiri. Oleh karena itu SAC dirancang dan dipersiapkan sedemikian rupa sehingga suasananya bisa tenang, aman, dan nyaman sehingga setiap orangyang masuk ke dalamnya dapat senantiasa belajar dan belajar

Armstrong, Michael (2007), dalam tulisannya "Self-Access: A framework for diversity" mengatakan bahwa self access centers dapat dibuat simple sebagaimana pernyataannya, "Self-access centers as a classroom set aside with dictionaries and shelves of paper-based exercises to state-of-theart digital centers with variousty pesof computer and internet based resources. What resources area vailableand how student sare guided touse them dependont he financial resources available and how much learner autonomy and institution decides to give students".

Demikian juga Sheerin (1990) sebagaimana dikemukakan oleh Ahsanuddin mendefinisikan self access center sebagai suatu cara untuk memberikan materi yang didesain dan disusun sedemikian rupa sehingga pembelajar dapat memilih dan mengerjakan tugas-tugas, serta dapat memperoleh balikan tentangperformansinya.Sementara itu, Aston sebagaimana Sheerin mendefinsikan SAC sebagai tempat individu untuk bebas memilih aktivitas dan menggunakan waktu untuk dapat belajar secara mandiri (Detarmani dan Chan, 1999).Tujuan dibangunnya fasilitas berupa SAC ini adalah agar seseorang dapat melakukan pembelajaran secara independen.

Dengan kata lain, SAC sebagai suatu pendekatan pembelajaran secara mandiri memungkinkan pembelajar menjadi individu yang bertanggung jawab, cerdas, dan memiliki motivasi. Melalui SAC, mereka dapat memutuskan secara efektif tentang apayang harus dia pelajari dan bagaimana dia mempelajarinya dari pilihan yang begitu luas. Lebih lanjut Chang (1999) mengatakan bahwa pebelajar dapat menentukan bidang apa yang harus diperbaiki dan metode apa yang disukai. Oleh karena itu, tepat yang dikatakan oleh Gardner dan Miller (1999), bahwa SAC, khususnya SAC pembelajaran bahasa itu pada dasarnya pendekatan untuk pembelajaran bahasa, bukan pendekatan untuk mengajarkan bahasa (Self •access language learning is anapproach to learning language, not anapproach to teaching language).

Menurut Sheerin dalam Ahsanudin (2006), SAC sebagai suatu carabelajar secara mandiri mereformasi posisi guru dan siswa yang terjadi dalam pembelajaran secara tradisional. Reformasi 
yang dimaksud adalah SAC sebagai suatu sistem dalam pembelajaran secara mandiri merupakan perpaduan antar elemen. Elemen yang ada dalam SAC pembelajaran bahasa menurut Gardner dan Miller (1999) dalam Ahsanuddin adalah:

1. Sumber (resources). Fungsinya adalah untuk menyediakan materi pembelajaran, materi yang otentik, kegiatan, teknologi, mengakses pengguna bahasa yang otentik, dan mengakses pembelajar bahasalain.

2. Masyarakat, meliputi guru dan pebelajar. Tugas guru adalah sebagai informan, konselor, pengguna bahasa, manajer, penulis materi, asesor, evaluator, administrator, dan organisator. Sementara itu, tugas pembelajar adalah sebagai perencana, organisator, administrator, pemikir, evaluator terhadap SAC, assessor diri, dan evaluator diri.

3. Manajemen, meliputi pengorganisasian, pengkoordinasian, pengambilan keputusan, melakukan hubungan denganlembaga.

4. Individualisasi. Fungsinya adalah menginformasikan adanya perbedaan indvidu yang meliputi gayabelajar, strategi belajar, waktu dan tempat belajar, tingkat pembelajaran, dan komitmen dalam belajar.

5. Analisis kebutuhan, yakni mengidentifikasi tujuan pembelajaran dan memudahkan penyusunan rancangan belajar.

6. Refleksi pembelajar, yaitu memperhatikan kemampuan bahasa, merefleksi kemajuan pembelajaran bahasa, dan merefleksi keberlanjutan SAC.

7. Konseling, memberikan saran yang berkaitan dengan belajar bahasa, metode pembelajaran, dan negosiasi perencanaan studi.

8. Pelatihan pembelajar untuk meningkatkan pemahaman SAC, memberikan pengalaman berbagai metode pembelajaran, dan meningkatkan efektivitas pembelajaran.

9. Pelatihan staf untuk meningkatkan pemahaman SAC dan meningkatkan efektivitas pelayanan.

10.Penilaian (Assessment). Jenis-jenis penilaian meliputi penilaian diri, penilaian antarteman, dan penilaianeksternal. Tujuan evaluasi ini untuk memonitor diri, sertifikasi, dan penilaian terhadap SAC itu sendiri.

11.Evaluasi. Memutuskan kesinambungan SAC dan memberikan balikan terhadap guru atau manajer SAC.

12.Pengembangan materi, mendukung individualisasi dan memperbaiki kesempatan belajar 


\section{TUJUAN PENGABDIAN}

Tujuan pengabdian pada masyarakat ini sebagai berikut:

1. Untuk memperoleh model dan media self access center yang efektif dan efisien yang dapat memfasilitasi anak putus sekolah

2. Untuk memperoleh informasi tentang kelayakan self access center yang diberikan dalam implementasinya.

3. Untuk mengarahkan anak putus sekolah dalam mendapatkan pengetahuan dan pengalaman lebih melalui pembelajaran self access center.

\section{MANFAAT PENGABDIAN}

Manfaat pengabdian pada masyarakat ini sebagai berikut:

1. Dapat lebih mensosialisasikan penggunaan self access center dalam dunia pendidikan, khususnya dalam pembelajaran untuk anak putus sekolah.

2. Dengan self access center ini, diharapkan anak putus sekolah dapat belajar sendiri dan menemukan sesuatu yang bermakna terhadap apa yang sedang dipelajarinya.

3. Dapat lebih mensosialisasikan program pengabdian pada masyarakat kolaborasi mahasiswa dan dosen, khususnya PGSD STKIP Siliwangi Bandung.

\section{E. METODE PENGABDIAN}

Adapun langkah-langkah kegiatan pengabdian yang akan dilakukan sebagai berikut:

1. Mengumpulkan anak-anak putus sekolah pada usia pendidikan dasar se-Kecamatan Cipatujah.

2. Memberikan gambaran umum mengenai kegiatan pengabdian yang akan dilakukan.

3. Melakukan refleksi dan diskusi mengenai berbagai kegiatan pembelajaran Self Access Center (SAC) yang akan dilakukan.

4. Melakukan kolaborasi dengan masyarakat sekitar dalam penentuan lokasi kegiatan pembelajaran Self Access Center (SAC).

5. Pelaksanaan kegiatan Self Access Center (SAC).

6. Evaluasi kegiatan Self Access Center (SAC).

\section{HASIL DAN PEMBAHASAN}

Kegiatan pengabdian pada masyarakat ini telah dilaksanakan di Desa Cipatujah, Kecamatan Cipatujah, Kabupaten Tasikmalaya pada tanggal 03- 09 Februari 2017 dan 
menghasilkan beberapa kegiatan yang sesuai dengan judul proposal yang diajukan pada UPT P2M yang di usung yaitu “Pengembangan Pembelajaran Inovatif melaluiSelf access center bagi Siswa dan Guru Sekolah Dasar di Kecamatan Cipatujah Kabupaten Tasikmalaya". Seperti yang telah dijelaskan pada bab sebelumnya, pengabdian pada masyarakat ini bertujuan untuk meningkatkan pemahaman guru mengenai pembelajaran melaluiself access center di Sekolah Dasar (SD). Hasil dan luaran yang dicapai pada kegiatan pengabdian ini sebagai berikut:

\section{Tabel 1}

\section{Rincian Kegiatan Pengabdian Di Kecamatan Cipatujah}

\begin{tabular}{|c|c|c|}
\hline No. & Hari dan Tanggal Kegiatan & Kegiatan \\
\hline 1 & Jumat, 03 Februari 2017 & Pemberangkatan ke Desa Sasaran. \\
\hline 2 & Sabtu, 04 Februari 2017 & $\begin{array}{l}\text { Sosialisai kegiatan pengabdian pada } \\
\text { masyarakatkepada Guru-Guru SD sekitar. }\end{array}$ \\
\hline 3 & Minggu, 05 Februari 2017 & $\begin{array}{lll}\text { Sosialisai kegiatan pengabdian pada } \\
\text { masyarakat. }\end{array}$ \\
\hline 4 & Senin, 06 Februari 2017 & $\begin{array}{l}\text { Sosialisai Kegiatan pengabdian pada } \\
\text { masyarakatkepada Guru-Guru SD sekitar. } \\
\text { Persiapan seminar pendidikan. }\end{array}$ \\
\hline 5 & $\begin{array}{l}\text { Selasa-Rabu, 07-08 Februari } \\
2017\end{array}$ & Pelaksanaan kegiatan seminar. \\
\hline 6 & Kamis, 09 Februari 2017 & $\begin{array}{l}\text { Penyerahan sertifikat ke UPTD Pendidikan Kec. } \\
\text { Cipatuahdan Ke SDN I Cipatujah. }\end{array}$ \\
\hline
\end{tabular}

Secara rinci, kegiatan-kegiatan yang telah yang dipaparkan di atas sebagai berikut:

1. Sosialisai kepada guru-guru SD se-Kecamatan Cipatujah.

Kegiatian ini dilaksanakan pada hari Sabtu, tanggal 04 dan hari senin tanggal 06 Februari 2017 dengan mendatangi UPTD Pendidikan Kecamatan Cipatujah, kepala sekolah inti di Kecamatan Cipatujah dan aparat Desa Cipatujah dengan tujuan untuk memberikan gambaran umum mengenai kegiatan pengabdian pada masyarakat prodi. PGSD dengan prodi. Lainnya di lingkungan STKIP Siliwangi Bandung, khususnya berkaitan dengan kegiatan yang akan dilaksanakan sesuai dengan judul yang di usung. 
2. Melakukan kolaborasi dengan guru-guru SD dan masyarakat sekitar dalam penentuan lokasi kegiatan seminar pembelajaran self access center .

Kegiatan yang dilaksanakan di Kecaamatan Cipatujah yaitu kegiatan seminar pendidikan dengan Tema "Meningkatkan Kualitas Guru". Penentuan tempat dan waktu kegiatan seminar tersebut melalui komunikasi dengan masyarakat sekitar dan kepala sekolah SD di lingkungan sekitar dan ditentukan tempatnya di Aula Desa Cipatujah dengan pertimbangan berada ditempat yang strategis sehingga mudah dijangkau oleh guru dari berbagai sekolah di Kecamatan Cipatujah.

3. Pelaksanaan kegiatan seminar dan evaluasi pembelajaran self access center .

Kegiatan seminar pembelajaran self access center dilaksanakan di Aula Desa Cipatujah, Kecamatan Cipatujah yang dilaksanakan selama dua hari yaitu pada tanggal 07 dan 08 Februari 2017 dengan ketentuan waktu dari pukul 08.00-15.00 WIB. Kegiatan seminar tersebut diisi dengan penyampaian materi yang berkaitan dengan pembelajaran self access center . Pada kegiatan seminar pendidikan tersebut dihadiri oleh 40 peserta yang berasal dari guru-guru SD yang ada di lingkungan Kecamatan Cipatujah.Setelah kegiatan tersebut terselengara, guru-guru SD yang mengikuti seminar pendidikan diberikan sertifikat kegiatan seminar yang diserahkan kepada UPTD Kecamatan Cipatujah dan kepada Kepala sekolah SDN I Cipatujah sebagai perwakilan untuk dievaluasi bagaimana dampak dari kegiatan seminar tersebut terkait pembelajaran self access center. Dari hasil wawancara terhadap salah satu kepala sekolah SD, didapat bahwa guru-guru SD yang mengikuti kegiatan seminar pendidikan tersebut mensosialisasikan hasil dari seminar kepada rekan-rekan guru lain di SD tersebut yang belum berkesempatan mengikuti seminar.

Dari hasil kegiatan pengabdian pada masyarakat yang telah dilaksanakan di Kecamatan Cipatujah Kabupaten Tasikmalaya didapat beberapa luaran yang sesuai rencana. Luaran yang sudah terlaksana seperti yang sudah dipaparkan di atas yaitu kegiatan peningkatan pemahaman dan keterampilan masyarakat dan jasa, model, rekayasa sosial, sistem, produk/barang melalui kegiatan seminar pendidikan yang ditujukan kepada guru-guru SD di lingkungan Kecamatan Cipatujah Kabupaten Tasikmalaya yang telah dilaksanakan di Aula Desa Cipatujah Kecamatan Cipatujah pada tanggal 07 dan 08 Februari 2017. Luaran selanjutnya yaitu publikasi ilmiah di jurnal/prosiding dan di media massa masih berupa draft yang akan di publikasi pada jurnal dan media massa yang sedang dalam proses. 
Selain luaran-luaran yang telah disampaikan, terdapat beberapa luaran sampingan diantaranya sebagai berikut:

1. Hasil-hasil program pengabdian pada masyarakat yang bisa dijadikan bahan sebagai data-data dan fakta untuk bahan kajian penyelesain tugas akhir (skripsi) / penelitian dan bisa dipublikasikan.

2. Adanya program tindak lanjut untuk tahun pengembangan program berikutnya berdasarkan evaluasi program, baik yang dilakukan oleh tim monev, maupun SD.

3. Bertambahnya siswa dan guru-guru SD yang melakukan pembelajaran self access center.

4. Tersosialisasinya program pengabdian masyarakat oleh PGSD STKIP Siliwangi Bandung melalui $\mathrm{x}$-banner dan spanduk-spanduk yang bisa memperkenalkan program ini semakin luas lagi sebagai bentuk hasil dari pelaksanaan program.

5. Adanya peningkatan pemahaman pembelajaran pada jenjang SD baik bagi siswa, maupun guru.

\section{E. KESIMPULAN}

Berdasarkan hasil pelaksanaan pengabdian pada masyarakat yang telah dilaksankan di Kecamtan Cipatujah Kabupaten Tasikmalaya, maka dapat disimpulkan hal-hal sebagai berikut:

1. Kegiatan pengabdian pada masyarakat ini bisa memberikan manfaat langsung kepada para guru, khususnya guru SD dalam meningkatkan pengetahuan, keterampilan, dan kesadaran menghargai proses kontruksi pengetahuan pada diri siswa.

2. Kegiatan pengabdian pada masyarakat ini dapat dijadikan sarana berinovasi dalam usaha mengembangkan model pembelajaran dan kualitas proses pembelajaran, khususnya di SD.

3. Wahana atau laboratorium bagi para dosen dalam mengimplementasikan teori, pengetahuan, dan keterampilan secara nyata, dan bermanfaat bagi masyarakat luas

\section{F. DAFTAR PUSTAKA}

Ahsanuddin, Mohammad. (2006). Media Pembelajaran. Tersedia: http://www.edukasi.net/artikel/index.php?id=83. (20 Agustus 2008) 
Armstrong, Michael. (2007). Seri Pedoman Manajemen: Manajemen Sumber Daya Manusia. Gramedia, Jakarta.

Chang, Richard Y dan Mark J Curtin. (1998). Membangun Tim Mandiri. PT. Pustaka Binaman Pressindo, Jakarta.

Nolen, S. B. (2003). Learning environment, motivation, and achievement in high school science. Journal of Research in Science Teaching, 40, 347-368.

Spitzer, D. R. (1996). Motivation: The neglected factor in instructional design. Educational Technology, 36(3), 45-49). 